Arqueología y Sociedad,

№ 22, 2010

\title{
UNA HIPÓTESIS ACERCA DE LA CUESTIÓN CRONOLÓGICA Y CONTEMPORANEIDAD DE LA ARQUITECTURA MONUMENTAl EN El COMPlejo DE PAMPa DE Llamas-MoXeke, valle de CASMA
}

Augusto Bazán Pérez*

\section{Resumen}

En el presente trabajo se plantea una hipótesis en base a la evidencia arquitectónica y al arte figurativo revisada por el autor, en torno a la cual se presume la diferenciación cronológica entre los dos montículos plataforma insertos en el complejo arqueológico de Pampa de Llamas-Moxeke en el valle de Casma. La diferenciación estilística en ambas líneas de evidencia, sumado a ciertos problemas en cuanto a los fechados radiocarbónicos, nos permite plantear que la Huaca Moxeke, postulada como centro de función religiosa, es el montículo principal propio del diseño original planeado para este complejo, representante del Patrón Casmeño definido por Carlos Williams (1980), mientras que la Huaca A con sus plazas hundidas (cuadrangulares y circular) anexas, pensada como depósito de bienes de élite (Pozorski y Pozorski 1986), posiblemente es una introducción tardía dentro del periodo Formativo Temprano (1800-1000 a.C.) que no respetó del todo al diseño original de construcción, construyendo en base a él de manera armónica sin infringir rupturas de orientación de los componentes arquitectónicos de forma dramática, innovación que quizá respondió a nuevos órdenes sociales tal vez relacionados al posterior despliegue del fenómeno Chavín.

Palabras clave

Pampa de Llamas Moxeke, Periodo Formativo Temprano, refinamiento cronológico, Fenómeno Chavín, estilos artísticos, Arquitectura Monumental Temprana.

\begin{abstract}
The present study raises a hypothesis based on the architectural evidence and figurative art reviewed by the author. We argue a chronological distinction between the two platforms mounds embedded in the archaeological site of Pampa de Llamas-Moxeke in the Casma Valley. Stylistic differentiation in both lines of evidence, plus some radiocarbon dates issues, suggest that the Huaca Moxeke, postulated as a center of religious function, is the main mound in the original design planned for this complex, representative of the defined Casma Pattern proposed by Carlos Williams (1980). While Huaca A, with associated sunken plazas (square and circular) intended as a repository of elite goods (Pozorski and Pozorski 1986), is possibly a late introduction into the Early Formative Period (1800-1000 B.C.). This building is intrusive to the original design of the site but based harmonically on it. The latter doesn't imply a strong change on the orientation of the architectural components and may represent an innovation due to new social orders perhaps related to the further deployment of the Chavin phenomenon.
\end{abstract}

\section{Keywords}

Pampa de Llamas Moxeke, Early Formative period, chronological improvement, Chavín phenomenon, art styles, early monumental architecture.

* Escuela Académico Profesional de Arqueología, Universidad Nacional Mayor de San Marcos.

Correo electrónico: ae.bazan.p@gmail.com 


\section{INTRODUCCIÓN}

Al momento de definirse el Patrón Casmeño como tradición arquitectónica de la Costa Norte y Nor Central de los Andes Centrales durante el periodo Formativo Temprano (1800-1000 a.C) siempre es preciso resaltar las diferencias formales entre los complejos que se enmarcan dentro de la misma situación. Sin embargo, es curioso que al momento de tratar al sitio de Pampa de LlamasMoxeke como representante de este patrón, se tenga la diferencia más grande con respecto a sus congéneres (Las Haldas y Sechín Alto solo en el valle de Casma). La diferencia más saltante es la presencia de dos montículos plataforma contrapuestos dentro del mismo complejo, situación que no existe para ningún otro caso en el valle de Casma, mucho menos en los valles más sureños, hasta el Fortaleza.

La evidencia arquitectónica y el arte figurativo nos permitirán sustentar la hipótesis nuestra, que plantea la diferencia cronológica entre el montículo principal del complejo, conocido como Huaca Moxeke (o Santa Matilde para los lugareños) y Huaca A, cada una ubicada en ambos extremos del complejo antes mencionado. Proponemos que el primer montículo es el montículo principal en el diseño original propio del patrón, en torno al cual giraban las actividades públicas en los primeros siglos del Formativo Temprano (y quizá los últimos del Arcaico Tardío como se verá al final) para la parte media del valle, mientras que el montículo Huaca A vendría a ser una introducción tardía dentro del mismo sub periodo, más relacionado a lo que luego sería el fenómeno Chavín en la Costa peruana.

\section{CAMBIOS Y CONTINUIDADES ESTILÍSTICAS DESDE EL Arcaico Tardío hasta el Formativo Medio. REVISIÓN DE LOS ESTUDIOS Y PROPUESTAS}

El periodo Formativo en los andes centrales ha sido y viene siendo extensamente estudiado por científicos de varias nacionalidades desde épocas en que Julio Cesar Tello redescubriera el sitio de Chavín de Huantar en la sierra nor central. Numerosos arqueólogos se han imbuido en problemáticas distintas, tratando de resolver preguntas planteadas por la tendencia teórica por sus tiempos en boga o elegida, sean estas de corte historicista cultural, materialista histórico o procesualista (Tello 1943, 1960; Larco 1938; Rowe 1967; Willey 1979; Proulx 1983; Dagget 1985; Lumbreras 1971, 1988; Burger 1986, 1992 , 1993; Pozorski, T. y Pozorski, S. 1987; Kaulicke 1994; Rick y Rodríguez Kembel 2004; Rick et al. 1999). Lo cierto es que para resolver estos problemas, y cualquiera que se pueda plantear independientemente de las corrientes teóricas planteadas, las líneas de evidencia predominantes siempre han sido tres: el arte figurativo, la arquitectura y la cerámica. Ya ampliamente superados los postulados que hiciera Tello (1943, 1960) en la primera mitad del siglo, con respecto a una Cultura Matriz de la civilización andina, a raíz de los hallazgos precerámicos de Junius Bird en Huaca Prieta (Bird 1948; Bird et al. 1985), se ha logrado detectar una secuencia de cambios y continuidades a lo largo de los periodos Arcaico Tardío (3000-1800 a.C.) y Formativo (1800-200 a.C), una tendencia que arrancaría durante el tercer milenio antes de nuestra era y que culminaría, como expresión máxima, en el denominado fenómeno Chavín.

Dicha tendencia ha sido detectada principalmente en base al estudio del arte figurativo desarrollado desde el 3000 a.C aproximadamente. Luego de los hallazgos producidos en Chavín y una tenue definición del estilo que a partir de dicho centro irradiaría hacia toda el área andina, los hallazgos siguientes comenzaron a poblar un mapa de recurrencias diacrónicas con grado de estilización progresiva dentro de este nivel de evidencia. Una vez refinada la periodificación para el área andina, luego de que John Rowe elaborara la secuencia maestra para los andes centrales, teniendo ya conocimiento de un complejo precerámico desarrollado previo a un periodo de cerámica inicial (Periodo Inicial), previo al fenómeno Chavín conocido como Horizonte Temprano (fechado por Rowe entre los 900-200 a.C.), los estudiosos pudieron establecer de una mejor manera las tendencias del devenir histórico del temprano arte centro 
andino. Estas últimas comenzaron a ser definidas desde lo más tardío dentro de este proceso, el estilo Chavín, hacia lo más temprano, las expresiones artísticas del Arcaico Tardío.

John Rowe (1967), arqueólogo que realizó grandes aportes por rescatar la historia prehispánica centro andina, realizó un primer intento por seriar el arte Chavín. Basado en las etapas de crecimiento del sitio de Chavín de Huántar, por él mismo identificadas, propuso una secuencia de desarrollo estilístico para el arte mayoritariamente esculpido en piedra procedente del lugar: fases $\mathrm{AB}, \mathrm{C}, \mathrm{D}$ y EF. Esta propuesta, sobre la cual se asientan la mayoría de discusiones concernientes al arte temprano centro andino ha de ser revaluada por los siguientes problemas: 1) Existe ya una representación más certera acerca del crecimiento del sitio de Chavín de Huantar. Silvia Rodríguez Kembel (2001) ha logrado determinar por lo menos 15 fases de construcción agrupados en cinco estadios. Esta secuencia ha demostrado que la simple explicación de Rowe concerniente al Viejo Templo y Templo Nuevo es insuficiente para entender la historia del crecimiento del monumento, mucho menos para entender sus implicancias a nivel macro regional, durante el primer milenio antes de nuestra era. La seriación del estilo Chavín, entonces, está basada en un estimado de crecimiento del sitio poco plausible. 2) La mayoría de piezas utilizadas por Rowe fueron procedentes del sitio pero sin certeza de sus contextos originales excepto por un solo espécimen: El Lanzón. Para el tiempo en que se elabora la propuesta aún no se había descubierto la secuencia de imágenes contextuadas en la plaza circular hundida. Se podría decir que solo se tiene certeza contextual de la cabeza de serie antes mencionada, pero la matriz arquitectónica, o de otra naturaleza, de las demás piezas parte de la muestra son desconocidas. La seriación en este par de puntos tiene grandes dificultades, ya que de no partir de una buena representación del crecimiento del sitio y de no tener a las piezas debidamente contextuadas, esta última responsabilidad ajena a Rowe desde luego, iqué tan plausible es la propuesta hoy en día a la luz de nuevos datos?
Henning Bischof $(1994,1995)$ tiene el mérito de haber definido un corpus de arte figurativo previo al fenómeno Chavín. Luego, en base a "semejanzas en la concepción artística" (Bischof 1995: 168) y su correlación con información estratigráfica y arqueométrica (fechados por carbono 14 y termoluminiscencia), logra la elaboración de una secuencia de desarrollo estilístico en los tres últimos milenios antes de nuestra era. De esta forma reconoce tres estilos: Punkurí, Sechín y Chavín A. El estilo Punkurí se caracteriza por ser abstracto, geometrizado y por tener diseños rígidamente convencionalizados, aún más que los demás estilos. Su expresión máxima o tipo vendrían a ser los murales de barro de la construcción más temprana del sitio de Punkurí en el valle de Nepeña (Bischof 1994: 179, 209-10). El estilo Sechín se caracteriza por su simplificación, mostrando líneas enérgicas y firmes que delinean representaciones tendiendo a ser más realistas que estilizadas, y por la ausencia de seres sobrenaturales, restringiendo las representaciones a seres antropomorfos y zoomorfos (felínicos y un pez). Ejemplos de este estilo serían todas las representaciones halladas en la arquitectura de adobe y la fachada de lápidas esculpidas del sitio de Cerro Sechín, así como en la fase constructiva superpuesta a los murales de barro del sitio de Punkurí, la que tiene como representante al felino modelado en bulto; sus garras, sus ojos bicorneanos y su ubicación temporal dada la superposición de fases constructivas abogan por su filiación al estilo en cuestión. Por último, el estilo Chavín $\mathrm{A}^{1}$ presenta una continuidad con respecto al estilo Sechín relativa al ojo bicorneano y la muñeca de doble arco, ambos rasgos precedentes directos de los

1 Se denomina como Chavín A a partir de que Rowe caracterizó su estilo Chavín $\mathrm{AB}$ con dos letras consecutivas pensando en que en algún momento se podrían encontrar los antecedentes del Lanzón, para él el exponente más temprano del arte Chavín clásico, y así poder discernir entre un arte pre y peri Chavín. Bischof mediante pruebas radiométricas determina un corpus de evidencia iconográfica inmediatamente previa a lo Chavín, y muy relacionada, a lo que pasa a denominar como Chavín A. El lanzón de Chavín de Huantar sería la obra de referencia del estilo Chavín B. 
rasgos más estilizados hacia el Formativo Medio. Se representan en este estilo a seres sobrenaturales, zooantropomorfos, deviniendo en una especie de barroquismo; la estilización de los diseños anteriores es diagnóstica. En comparación a sus predecesores, Chavín A fue muy difundido de manera tal que no se restringió a la sierra nor central. Muchos ejemplos se hayan tanto en costa como en sierra, determinándose rasgos recurrentes para este estilo tales como los seres antropomorfos de Yura-yaco, los personajes fieros supernaturales y las máscaras agnáticas, presentes conjunta o individualmente en Strombus provenientes de Chiclayo, en platos de piedra de Limoncarro y un petroglifo en Tolón en el valle de Jequetepeque, en representaciones en piedra provenientes de la Galgada en la quebrada de Tablachaca, en La Pampa ubicado en el Callejón de Huaylas y en cerámica de Purulén en el valle de Zaña (Bischof 1994:181-182). Trataremos más adelante acerca del último rasgo citado.

Se han mencionado solo dos autores, quienes a nuestro parecer han sentado las bases de lo que es el estudio de la iconografía temprana centro-andina para fines de refinamiento cronológico y establecimiento del desarrollo estilístico. Sin embargo ello no quiere decir que sean los únicos. Acerca del tema se ha tratado en extenso por lo que la literatura derivada es abundante. No obstante dicha situación existe hasta el momento un problema, ya detectado desde temprano, pero de muy difícil mitigación: La contextualización de la muestra. A pesar de los esfuerzos de Bischof por lograr contrastar la iconografía, sobre todo de matriz arquitectónica, con los momentos de crecimiento de los sitios y los datos arqueométricos ${ }^{2}$, el universo de su muestra empleada no

2 Lo cual es un tanto difícil en tanto dichas representaciones artísticas (relieves de barro, frisos, lápidas, pinturas rupestres, etc.) no pueden fecharse por sí mismas. Se ha de tener un buen registro del crecimiento estratigráfico de los asentamientos para luego poder estimar la edad relativa de dichas representaciones. Para ello se debe contar con una buena metodología de recojo de las muestras a fechar, procedentes de contextos confiables, y con la certeza de la ubicación de estratigráfica de dicho contexto para poder extrapolarlo a la representación artística. solo procede de arte mural, sino de cerámicas, espátulas y morteros, más de las veces descontextuados, procedentes de colecciones privadas de distintos lugares. Se podría decir que gran parte de lo que conocemos del temprano arte centro andino procede de este tipo de objetos, recuperados mediante el saqueo sistemático de los asentamientos, llámese "huaqueo", lo cual para nada da una imagen precisa de sus contextos, muchas veces ni siquiera de la zona o sitio de procedencia específico. Otro problema es el que implica relacionar a todas las expresiones artísticas (representaciones figurativas) sin tomar en cuenta el soporte sobre el cual se asientan, la variabilidad representacional que esto implica y la funcionalidad de estos objetos en las prácticas sociales. Al considerar únicamente la expresión artística y no considerar la matriz o soporte del que procede y en el que se encuentra representado, vale decir al no reparar en la gran figura llamada contexto, y no hacer una contrastación sobre estos objetos que hacen líneas de evidencia distintas, puede correrse el riesgo de encontrar errores en los planteamientos e interpretaciones. Vega-Centeno (1998), luego de recomendar la documentación del tipo de soporte para precisar mejor la muestra comparativa, entre otros puntos, refuta a Bischof el planteamiento de la segregación de los estilos Punkurí y Sechín, dado que existen varios contextos donde ambos coexisten, supuestamente dentro de Huaca Moxeke, Punkurí y en las piezas del Museo Bruning, por lo que plantea que ambos estilos son en realidad un conjunto de recursos sincrónicos para la representación artística.

Vemos así entonces un panorama que se aclara, dado que se han logrado identificar las tendencias del arte prehispánico desde el Arcaico Tardío hasta el Formativo Medio, o sea el tránsito de expresiones geométricas hacia realistas y el tránsito de organización por adición de diseños hacia la organización por integración de los mismos (Bischof 1995). Estos estudios son y serán prometedores en tanto a futuro se logre incrementar la muestra con los debidos controles estratigráficos y contextuales. En tanto hayan más hallazgos relativos al arte prehispánico, con- 
vertidos en datos empíricos con las cualidades necesarias para poder ser incluidas en una muestra maestra, la cual para los estudios luego sea contrastada según línea de evidencia. Las interpretaciones y planteamientos de ellos derivados tendrán un margen de error mucho más bajo.

\section{El Complejo de Pampa de Llamas - Moxeke en} el espectro del Patrón Casmeño

El sitio consta de dos montículos principales, Huaca Moxeke o Santa Matilde (así conocida por los lugareños) al sur y Huaca A al norte. Ambas estructuras principales se encuentran frente a frente y están vinculadas por un conjunto de plazas consecutivas cuadrangulares de grandes dimensiones, formando el eje principal del complejo. Asociados a este eje principal tenemos más de un centenar de recintos y montí- culos de tamaño intermedio, a lo que se denomina áreas de arquitectura intermedia. Todo el asentamiento cubre un área de 220 ha (Pozorski y Pozorski 2000). La Huaca Moxeke, situada al sur del complejo, actualmente está rodeada por tierras de cultivo y por una vía carrozable hecha luego de la Reforma Agraria de 1968, mientras que la Huaca A, sus plazas rectangulares frontal y trasera, su pozo circular trasero, la arquitectura intermedia y unas cuantas plazas que conectaban antes esta estructura con Huaca Moxeke, se emplazan sobre una terraza aluvial o pampa, la cual no ha sido afectada por la agricultura, aunque si por eventos climáticos. El actual canal de Purgatorio, canalizado en la década de los 80, hace las veces de límite o frontera entre esta terraza aluvial y el área agrícola y deja muchos perfiles expuestos a lo largo de su curso, notándose en ellos ocupaciones más tardías, por

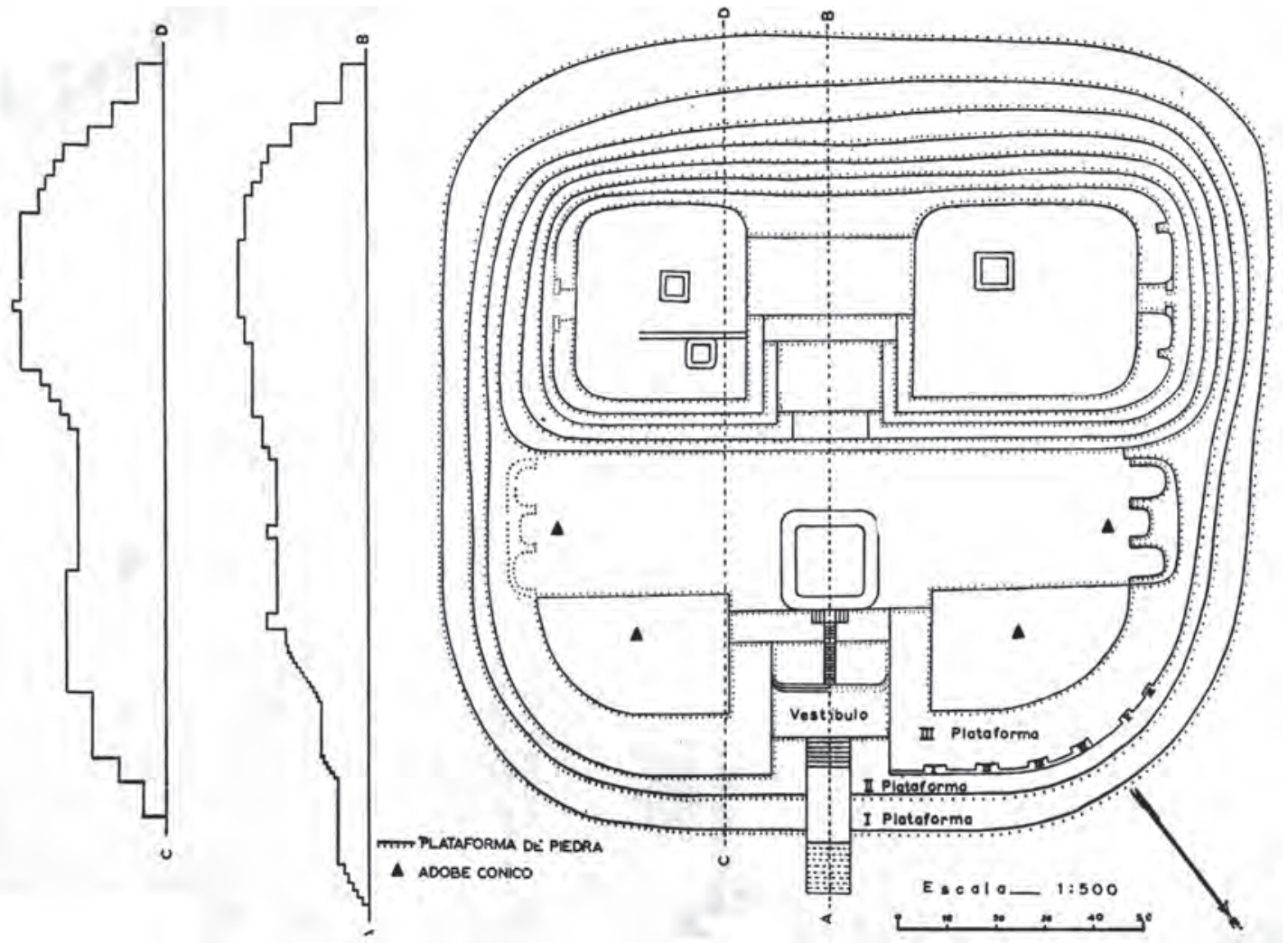

Figura 1: Plano de Huaca Moxeke, con cortes transversales de elevación a la izquierda y ubicación de los "ídolos" de barro hacia la esquina norte de la tercera plataforma. (Tomado de Tello 1956: 57, fig. 25). 


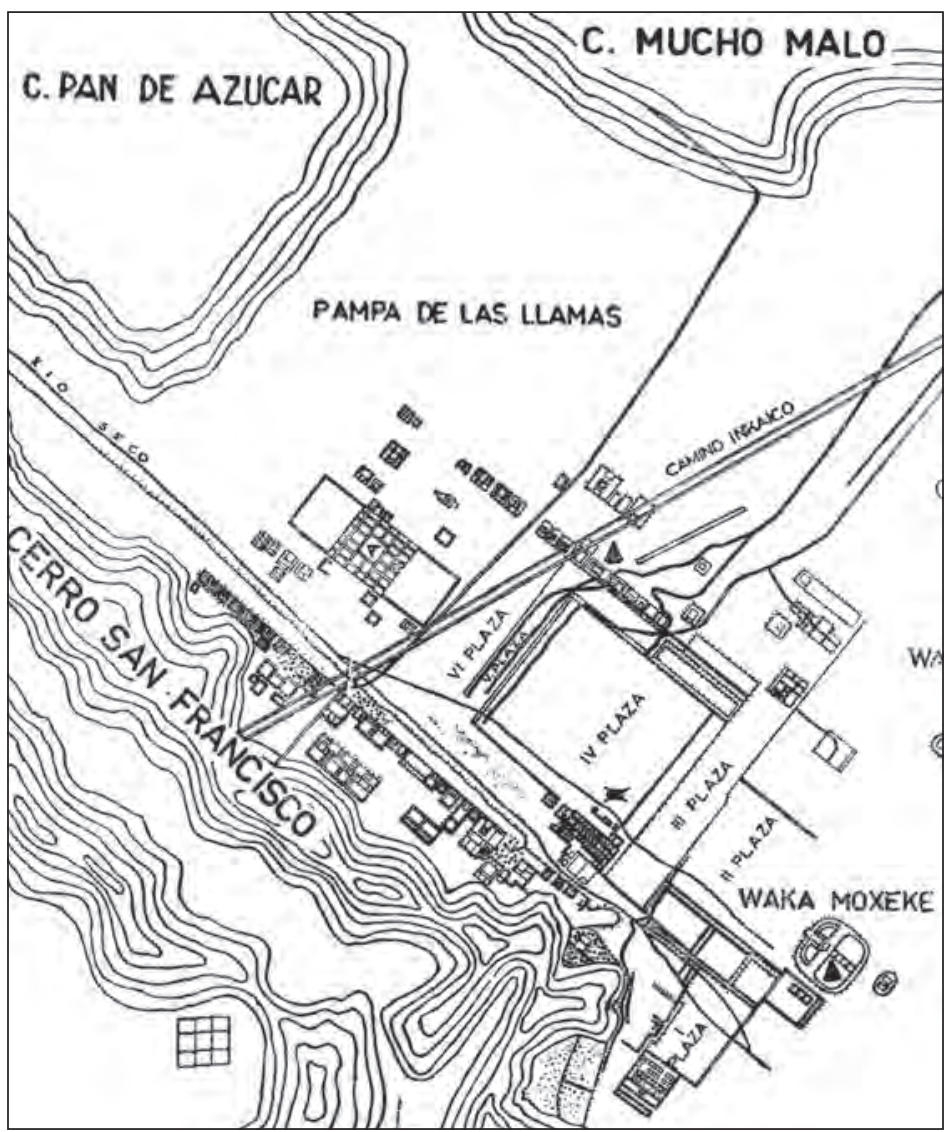

Figura 2: A pesar de su antigüedad, Tello elabora este plano el cual tiene las cualidades de ser meticuloso en cuanto a la representación de los componentes arquitectónicos del complejo y por circunscribirlos a las estribaciones que lo rodean, siendo esto crítico al momento de determinar orientación, crecimiento y funcionalidad del asentamiento. (Tomado de Tello 1956)

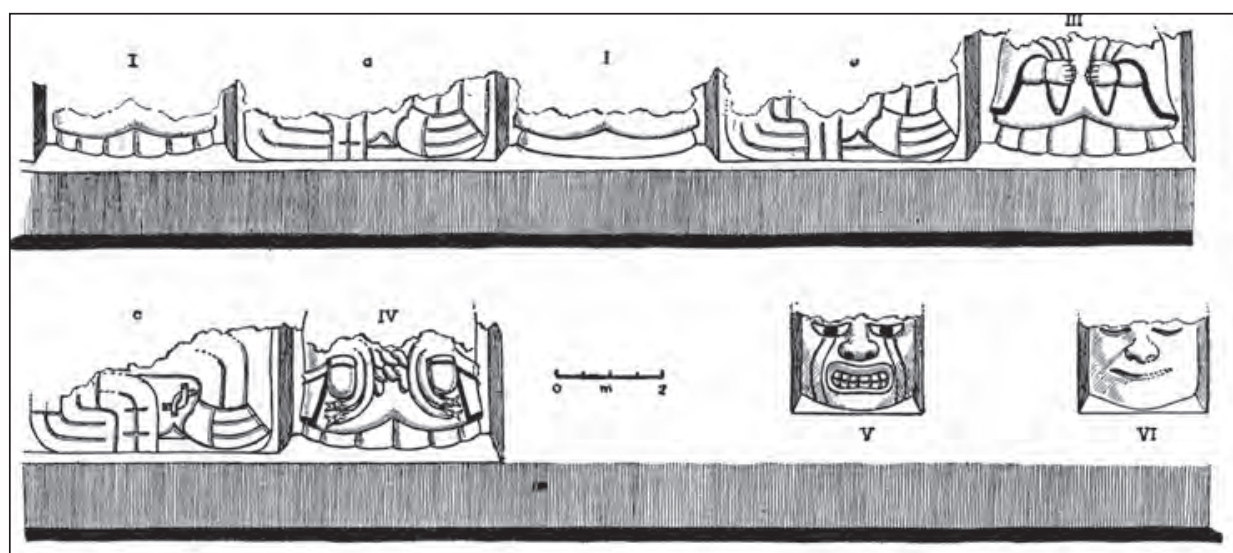

Figura 3: Vestigios de "ídolos" ubicados en la esquina norte de la tercera plataforma de Huaca Moxeke (tomado de Tello 1956: 61, fig.27) 
la presencia de cerámica de estilo Casma Inciso (Bazán 2008a).

Harto conocidos son los trabajos que Julio C. Tello hiciera por los años 30 en el sitio de Huaca Moxeke (Tello 1956). El logro más saltante y conocido de esta campaña fue haber definido de una forma muy precisa el último evento de construcción de este montículo, elaborando un plano con detalles muy certeros (Fig. 1), muchos de los cuales se perdieron luego del terremoto de 1970, así como de todo el complejo en cuestión, delimitando los accidentes geográficos a los cuales todo el asentamiento se circunscribe (Fig. 2).

Mediante la limpieza de la cima del montículo para la definición arquitectónica y las excavaciones (las cuales no están bien documentadas), se descubrieron hacia la esquina curva norte, en la fachada de la tercera plataforma, seis vestigios de "ídolos" o personajes modelados en bulto, ubicados en especies de cajones empotrados en la fachada de la plataforma antes mencionada, separados por representaciones geométricas ubicadas en los excedentes entre-cajones, al nivel del contorno de la misma esquina curva del montículo (Fig. 3).

Tello asociaría el arte desplegado en Huaca Moxeke al fenómeno Chavín en la costa peruana. La seriación que hiciera Donald Thompson (1964) para la arquitectura monumental temprana en el marco de los trabajos de Donald Collier (1962) en el valle de Casma, ubicarían también a dicho montículo en el Formativo Medio (750. 400 a.C) asociándolo al estilo cerámico Patazca, derivativo del estilo Chavín. A inicios de la década de los 70 Rosa Fung (1972) fecha a la ocupación principal del asentamiento para el Periodo Inicial y hacia fines de los 80 , Shelia y Thomas Pozorski (1986, 1987, 1989) desarrollaron investigaciones en la parte mejor conservada del complejo, la que da a la pampa y alejada del área arable donde se encuentra la Huaca Moxeke (junto con arquitectura intermedia), concentrando sus esfuerzos en la Huaca A, montículo contrapuesto y mencionado al comienzo de este apartado. Sus trabajos han logrado confirmar la fecha pre-Chavín de este asentamiento, por medio de fechados radiocarbónicos, confirmando la ubicación cro- nológica del sitio dentro del periodo Formativo Temprano.

El despliegue arquitectónico de Pampa de Llamas-Moxeke no es patrimonio únicamente del sitio. Dicho patrón, definido por Carlos Williams (1980: 408-410), es recurrente en sitios arqueológicos que no solo se presentan en el valle de Casma y tiene básicamente dos condicionantes o rasgos diagnósticos: a) configuración de planta con forma de "U" en el Montículo Principal, delimitado por la presencia de una escalinata central y atrio en el montículo plataforma, y b) la presencia de las plazas rectangulares consecutivas en base al axis longitudinal que marca el mismo montículo. A parte de estar presente en los sitios de Las Haldas, Pampa de Llamas-Moxeke, Sechín Alto y TaukachiKonkan, según nuestras observaciones el patrón mencionado quizá pueda también estar presente en el valle de Chao; en el valle de Culebras, sitio de Culebras, y en el valle de Huarmey, en los sitios de Mandinga y Mal Paso (Cárdenas 1999; Álvarez y Espinoza 1997; Lanning 1967; Bazán 2010: 37). En un trabajo previo tratamos acerca del sitio de Huaricanga, en el valle de Fortaleza, el cual posiblemente se enmarcó dentro de esta tradición arquitectónica tardíamente, hacia fines del Formativo Temprano, debido a la aparición tardía y superpuesta a la arquitectura original de las plazas cuadrangulares consecutivas. Este sitio presenta la característica de tener dos montículos laterales, de menores dimensiones en contraste al montículo principal, lo que configura un complejo de edificios con planta en "U", tradición arquitectónica diferente y más recurrente en la costa central, por lo que propusimos para el sitio en cuestión una convergencia de tradiciones en tanto sus dos momentos definidos en base a evidencia superficial (Bazán 2010: 37-45).

Todos los complejos vinculados al patrón casmeño tienen un montículo principal, el cual se distingue por los rasgos antes citados y por su monumentalidad, lo que implica una relevancia visual en todo el paisaje visual del asentamiento. Sin embargo, Pampa de Llamas-Moxeke presen- 
ta dos montículos claramente monumentales y opuestos, mirándose directamente de extremo a extremo dentro del mismo complejo. Esta situación es totalmente atípica, siendo única en la amplia gama de sitios tempranos en la costa centro andina. De momento esta situación solo tiene una interpretación publicada, la de Shelia y Thomas Pozorski, quienes sostienen que ambos montículos funcionaron sincrónicamente. Huaca Moxeke sería el centro del poder ideológico y las actividades religiosas para este complejo, dominante de la escena política en el valle medio durante el Formativo Temprano, mientras que Huaca A sirvió como depósito de almacenamiento de bienes que constituyeron el poder económico de la élite del sitio (Pozorski y Pozorski 1986: 383-4).

\section{LA CUESTIÓN DE LOS FECHADOS RADIOCARBÓNICOS}

Shelia y Thomas Pozorski (1986, 1987), sostienen que los dos montículos dentro del complejo, en otros tiempos discriminados uno del otro y ahora agrupados dentro de la misma situación, funcionaron al mismo tiempo pero con funciones o roles diferentes, tal como se menciona líneas arriba. Sin embargo esto no está probado. Una de las razones por las que sostenemos esta idea es que no se cuentan con fechados radiocarbónicos para Huaca Moxeke. Las excavaciones arqueológicas de Tello, en la década de los 30, fueron previas a la invención del método de carbono 14, y Donald Collier y Donald Thompson, aunque ya inventada la técnica, durante la ejecución de sus pozos de prueba en 1956 no tomaron muestras. Los únicos fechados con los que se cuentan son los que Shelia y Thomas Pozorski han tomado a lo largo de sus campañas de excavación. De los 24 fechados radiocarbónicos disponibles para el complejo, solo tres fechados proceden del mismo montículo, los cuales supuestamente fechan su última etapa de construcción. Pequeños pozos de prueba han demostrado una etapa previa de ocupación, la penúltima cuando menos, la cual es similar en forma y orientación a las cámaras superpuestas. Lastimosamente no se ha fechado dicha etapa constructiva y la cantidad de información hasta ahora publicada, o recuperada, nos parece escasa para asignarle funcionalidad a esta temprana construcción. Los fechados para el montículo son UGa-5794 [3185 \pm 60 BP], UGa-5462 [3515 $\pm 70 \mathrm{BP}]$ y UGa-5873 [3105 $\pm 30 \mathrm{BP}]$. Las fechas provienen de muestras de madera de la última fase de ocupación. El fechamiento de madera tiene dos problemas tangenciales, el primero denominado "madera antigua" (Old Wood Problem) que implica los problemas que trae el fechar muestras de madera que tal vez ha sido utilizada y reutilizada por varias generaciones (posiblemente en la etapa constructiva anterior habida cuenta la continuidad en el patrón de restricción de accesos mediante trabas de madera), y el segundo denominado "núcleo de la madera" (Heart Wood Problem), que sucede cuando la muestra tomada proviene de anillos antiguos de crecimiento y no de los relacionados al evento de corte y utilización primigenia. Estos problemas conllevan a fechas alteradas y se ha comprobado mediante experimentos que el desenlace consiste en el arrojo de fechas muy tempranas, creando un gran error y confusión si no se advierte la situación a tiempo (Burger 1989).

Cabe resaltar que de las 24 fechas disponibles para el sitio, la mitad de ellas (12) fueron tomadas en base a madera, además, los contextos de las muestras no son lo suficientemente claros. A esto se suma el hecho de que las fechas no han sido calibradas.

Esto no nos da una idea clara acerca de la antigüedad y crecimiento por lo menos del montículo, en asociación con la arquitectura intermedia, la cual tiene las 21 fechas restantes. En resumidas cuentas se ha querido fechar el universo del complejo en base a la arquitectura intermedia, lo cual de por sí ha sido un intento fallido habida cuenta la metodología de recolección de muestras. Este intento de extrapolación ha intentado relacionar todas las diferencias en la arquitectura y en el arte figurativo del complejo como manifestaciones sincrónicas. Lo que aquí proponemos es contrario a esta situación. Como se verá más adelante, el hecho de que las fechas 
para Huaca A puedan ser más antiguas de lo que se piensa ${ }^{3}$ contribuye a nuestra hipótesis, relativa a que la construcción del montículo en cuestión es posterior e impuesta a la Huaca Moxeke y el despliegue arquitectónico de sus plazas cuadrangulares asociadas.

\section{DiFERENCIAS ESTILÍSTICAS EN LA DIMENSIÓN ARQUITECTÓNICA E IMPLICANCIAS}

Como se dijo en el apartado anterior, desde la década de 1980 se viene argumentando que las diferencias formales entre los montículos monumentales dentro del complejo responden a una lógica funcional antes que cronológica. Las diferencias en tanto distribución arquitectónica interna de los monumentos, así como en la utilización de materiales para lograr dicha distribución y acabado, parecen ser consistentes con el planteamiento a primera vista (Fig. 4).

La Huaca A mide $125 \times 110 \mathrm{~m}$ y cuenta con una altura aproximada de $12 \mathrm{~m}$. Su forma es ligeramente romboide. Sus plazas cuadrangulares frontal y trasera son hundidas, excavadas en la superficie natural de la pampa y las dimensiones de estas son de $125 \times 110 \mathrm{~m}$ con una profundidad aproximada de $2 \mathrm{~m}$. Detrás de la plaza cuadrangular trasera se ubica una plataforma de $40 \times 60 \mathrm{~m}$ con una altura relativa de $3 \mathrm{~m}$, descubierta por los Pozorski, en la cual se inscribe una plaza circular hundida de un diámetro aproximado de 35 m (Fig. 5). La complejidad de la organización interna del montículo es única en la costa peruana. Hay dos accesos principales, de manera que cada

3 Dado que se han fechado varias estructuras menos la Huaca Moxeke, podríamos decir que se puede tener una edad estimada de dicha porción. Al principio, antes de la discusión con Burger (1989), se planteó la ocupación de dicha porción entre 1800-1100 a.C. Luego de la mencionada discusión, y haciendo arreglos sobre sus interpretaciones a la luz de nuevos fechados (algunos de los cuales con los mismos problemas), Pozorski, T. y Pozorski, S. (1990) reubican la probable fecha de ocupación del asentamiento entre el 1600 al 1200 a.C., reconociendo que la historia de crecimiento del sitio es mucho más compleja de lo que ellos pensaban. Por último estiman que la última etapa de construcción de Huaca A estaría ubicada entre los 1300 y 1200 a.C. plaza vendría a ser un paso previo a la entrada. Si uno accede al edificio tanto por delante como por detrás, se alcanza un área central baja ${ }^{4}$; la altura de los recintos crece a medida que uno se dirige a las partes laterales. La cima del montículo está formada por numerosos cuartos regularmente dispuestos. El montículo es bilateralmente simétrico, de manera que si uno divide la cima del mismo en cuatro cuartos, se nota que el patrón de aparición de los recintos es idéntico (Pozorski y Pozorski 1986: 385; 1987: 33-5). Mencionaremos en adelante una plaza frontal y una trasera, dado que por más que ambos accesos conlleven a exactamente el mismo tipo de cámaras, en tanto número como dimensiones de las mismas, la plaza y acceso sureño mira hacia el grueso del asentamiento, incluyendo Huaca Moxeke, y tiene dominio visual directo sobre el valle, mientras que el acceso norteño mira hacia la quebrada ${ }^{5}$ y el cerro Pan de Azucar. Los muros aun conservados de la Huaca A miden un promedio de 1.5 metros. Los Pozorski estiman la altura original de los muros, en base a sus excavaciones, entre 4 y 7 metros. En general se componen de rocas de gran tamaño (boulders) en su mayoría angulares y traídas en gran parte desde la ladera del cerro contiguo. Rocas de tamaño regular proceden de la misma fuente. La gran mayoría de las piedras no son trabajadas, o sea no se les ha dado una forma intencional, sin embargo, sus caras más planas son utilizadas para delinear las caras de los

4 Vale la pena resaltar que Julio C. Tello, en esta misma área, el cuarto central, encontró un poco de huaqueo que había develado "una gran piedra, al parecer no labrada, de $3 \mathrm{~m}$ de longitud por $20 \mathrm{~cm}$ de ancho y $60 \mathrm{~cm}$ de espesor, aparte de algunos fragmentos de cerámica chavín clásico" (Tello 1956: 52).

5 Esta quebrada actualmente, aunque más utilizado en tiempos de la Hacienda San Rafael, es un camino que se utiliza para llegar a la ciudad de Casma vía Pampa Rosario, lugar donde se encuentra el asentamiento homónimo que data del periodo Formativo Medio. Es posible que esta quebrada haya sido utilizada como un paso de salida y entrada del complejo en cuestión, y que Huaca A domine al mismo por su lado norte, sin embargo esta es una idea aun poco desarrollada, dado que habría que evaluar las direcciones que este paso pueda tomar, trayectorias que pueden dirigirse bien hacia el valle bajo, tal como ahora, bien hacia el valle alto, hacia el este, la sierra, el Callejón de Huaylas. 

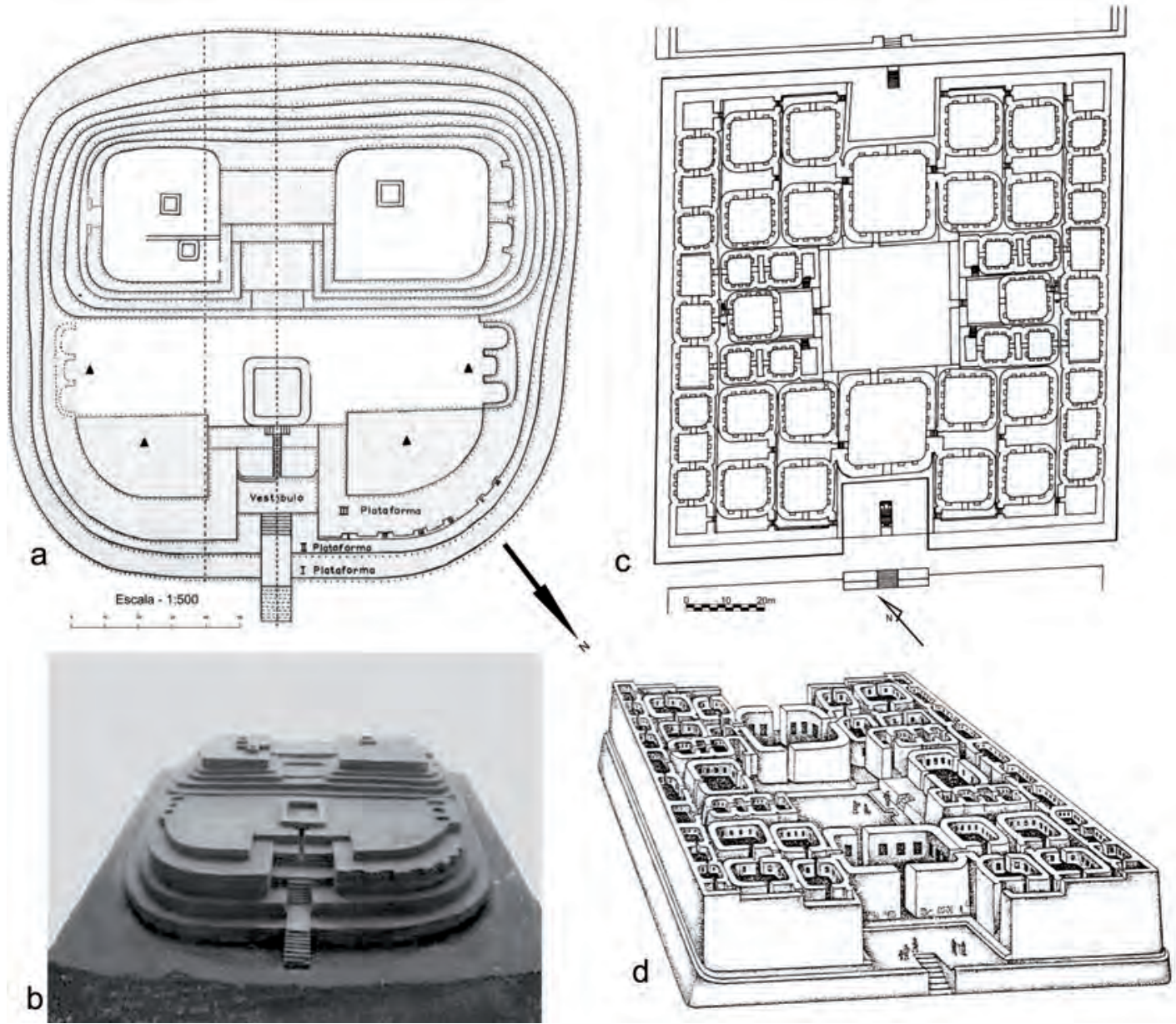

Figura 4: Contraste entre Huaca A y Huaca Moxeke. a) Vista en planta de Huaca Moxeke, redibujado a partir de Tello 1956: 57, fig. 25. b) Maqueta de Huaca Moxeke ubicada en el Museo Regional Max Uhle de Casma. c) Plano de Huaca A, redibujado a partir de Pozorski, T. y Pozorski, S. 1988: 115, fig. 1. d) Reproducción de lo que alguna vez podría haber sido Huaca A, sin incluir sus plazas adyacentes y vista desde el noreste, tomado de Burger 1992: 84, fig. 67.

muros, los cuales son de doble cara. El mortero utilizado es de color marrón compuesto por sedimentos de lecho de rio, material que también fue usado para ciertos enlucidos en ciertos recintos. Existe evidencia de nichos en los tercios superiores de los muros, la utilización de adobes cónicos es exigua y es recurrente la utilización de umbrales elevados en los accesos a las cámaras o recintos (Pozorski y Pozorski 1986: 386).

Huaca Moxeke, en cambio, es distinta en cuanto a construcción. La utilización de grandes piedras megalíticas, trabajadas y bien labradas es recurrente. Los adobes cónicos son ubicuos por todo el monumento. Al igual que Sechín Alto, Las Haldas y Huaricanga, está construido mediante un sistema de plataformas superpuestas, rectangulares o ligeramente elípticas. Esto último demuestra la intención de los arquitectos del montículo por lograr cada vez mayor altura y contrasta fuertemente con la intención primigenia de los arquitectos de Huaca A.

La impresión que brinda el hecho de que Huaca Moxeke se eleve $30 \mathrm{~m}$ y que Huaca A se eleve tan solo 12 , se ve invertida al contras- 


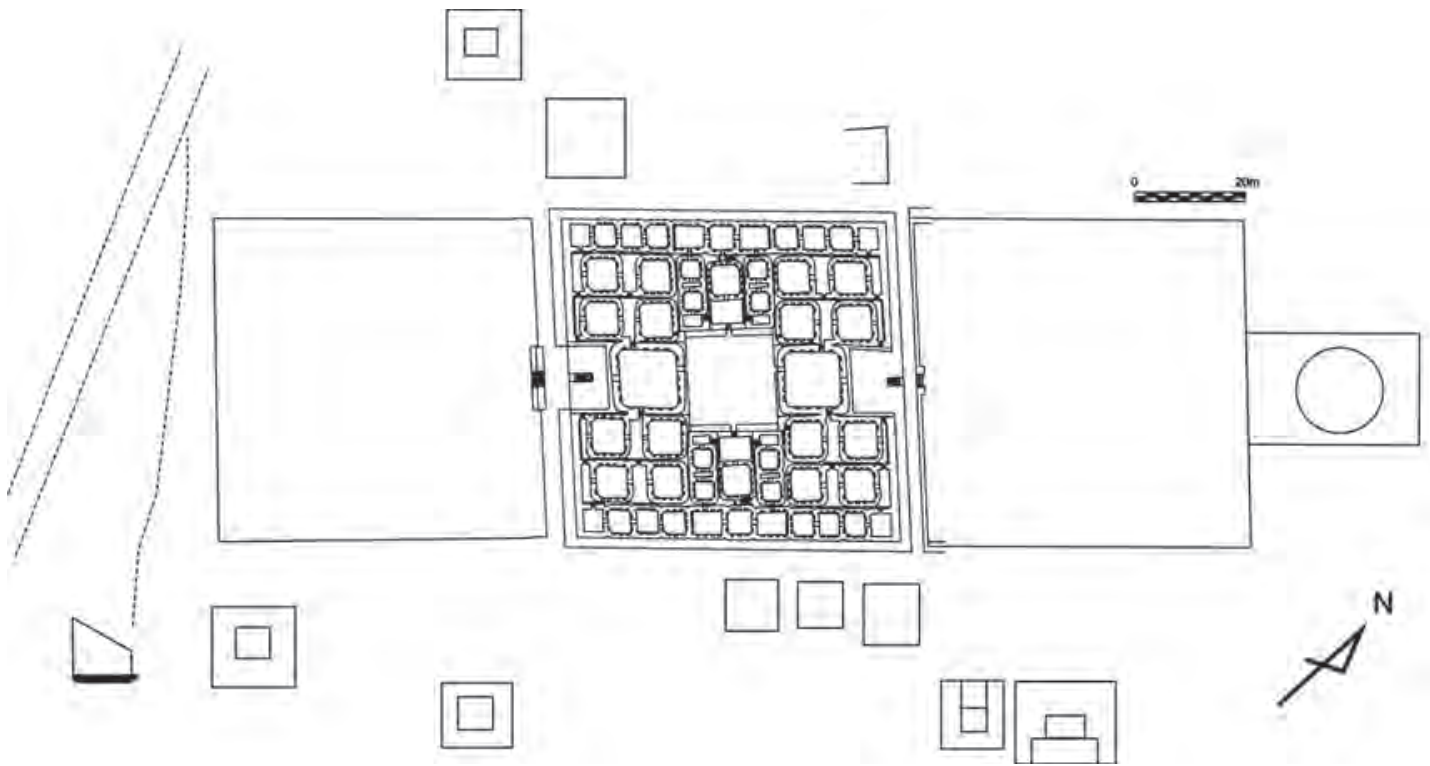

Figura 5: Plano de Huaca A, sus plazas asociadas y pequeños montículos anexos. Redibujado en base a Pozorski, S. y Pozorski, T. 1986, fig. 2 y Pozorski, T. y Pozorski, S. 1988: 115, fig. 1.

tar dicha diferencia con respecto a la topografía del lugar. Mientras que Huaca Moxeke se asienta sobre los 120 m.s.n.m. aproximadamente, Huaca A se asienta sobre los 150 m.s.n.m., creando una diferencia relativa de $30 \mathrm{~m}$ en cuanto al emplazamiento de cada monumento. Si sumamos a estas superficies la altura promedio de los montículos veremos que la cima de Huaca A tiene una ventaja de $12 \mathrm{~m}$ por sobre la altura de Huaca Moxeke. Dicha estrategia de utilización del relieve topográfico en pos de ganar altura no parece casual habida cuenta que por lo general dicho hecho, el de lograr una mayor altura y mayor complejidad (en tanto a la distribución espacial interna de Huaca A), es sintomático de una lógica de prestigio y poder socio-político. El habilitamiento de la superficie de la quebrada para construir las plazas hundidas, de grandes dimensiones, debió haber demandado cuantiosa mano de obra y tiempo para la remoción de miles de metros cúbicos de tierra y la construcción de los aparejos que orlan las plazas. Todo lo mencionado provoca hacerse las siguientes preguntas: ihay necesidad de tanta monumentalidad, no solo en la obra material sino en la fuerza invertida, tanto para excavar como para erigir, para depositar bienes de élite?, ¿es fortuita la ubicación elevada de la Huaca A y sus plazas adyacentes? Pensamos que no existe necesidad de tanta inversión de tiempo y trabajo para lograr un depósito de grandes dimensiones ${ }^{6}$ exclusivamente para bienes de élite. La presencia de nichos y de roedores en los cuartos excavados puede ser sometida a lecturas distintas que las planteadas por Shelia y Thomas Pozorski. El patrón de accesos de Huaca A claramente denota un control por quien accede al monumento; las dimensiones de los cuartos sugieren que no muchas personas pudieron concentrarse en ellos. Las plazas anexas a Huaca A son totalmente distintas a las que se despliegan a partir de Huaca Moxeke, las cuales están elaboradas en base al estilo terraplén, lo que implica elaborar un aparejo cuadrangular con mínima remoción de tierra o adecuación de la superficie, y tienen dimensiones más o menos coherentes o proporcionales entre sí. En ciertos casos hay plazas que parecen levemente hundidas, sin embargo esto es un efecto visual creado por la aparición de grandes plata-

6 Cabe anotar que aunque de menores dimensiones que Huaca Moxeke, la Huaca A sigue siendo monumental por más que su altura parezca decir lo contrario, tal como se ha venido argumentando líneas arriba. 
formas que las delimitan. Las plazas de Huaca A no son coherentes con el universo de plazas que cruzan mayoritariamente por todo el complejo, y son hundidas, lo cual implica que la lógica de construcción es muy distinta, habiendo demandado otro tipo de condiciones. Debido a que no tenemos un informe in extenso acerca de las excavaciones y los materiales provenientes de dicho montículo, presumimos que la distribución interna de los cuartos en la cima de Huaca A pudo haber correspondido a ritos de pasaje restringidos a élites privilegiadas y de número muy reducido debido a la poca capacidad de congregación que tienen las cámaras del sitio. La ausencia de los llamados bienes de élite hace caer por sí sola la idea del monumento como suerte de depósito, las cámaras fueron encontradas vacías y por lo general limpias ${ }^{7}$ (excepto por algunas cerámicas, no bien reportadas, cientos de restos de roedores en los nichos y en las cámaras, cuentas de turquesa, algunos restos de textiles y una figurina de madera, todos en cantidades para nada representativas) lo cual, a pesar de parecer evidencia negativa, muchas veces es indicador de ambientes rituales. Los ritos de pasaje tienen connotaciones rituales y tienen que ver con las prácticas sociopolíticas de la sociedad que se desarrolló en dicha parte del valle, prácticas que establecen las formas políticas e ideológicas de ordenación social unidireccional y que son destinadas a establecer formas de cooperación o distancia social (Castro et al. 1996).

Si es que en realidad esta era la función designada para la Huaca A, ¿Qué rol tenía entonces Huaca Moxeke? Pensamos que el mismo. Tal como se dijo al comienzo, pensamos que Huaca A y sus plazas cuadrangulares y circular son una intrusión en lo planificado para el complejo en cuestión, en la que Huaca Moxeke era el centro de todas las actividades y era coherente con el Patrón Casmeño en el cual se

7 El hecho de la ausencia de bienes suntuosos (emptiness), según Shelia y Thomas Pozorski, refuerza el planteamiento relativo a Huaca A como centro de almacenaje debido a que se supone dichos bienes fueron retirados apenas el sitio dejó de ser ocupado (Pozorski, S. y Pozorksi, T. 1986: 387). enmarca. Huaca A modificaría construyendo sobre la lógica de este patrón, pero alterándolo de plano hacia finales del Formativo Temprano. El patrón de acceso a Huaca Moxeke se realiza por una sola vía, la parte frontal del montículo por medio del corredor central. Las dimensiones de la explanada previa a la doble cima de la Huaca, en donde también se encuentra un atrio, supone la congregación de un número representativo de personas. Desde ese punto hacia arriba, hacia los llamados "torreones", los espacios se acortan, permitiendo un flujo menor de sujetos. Se puede colegir entonces un tránsito de personas mayor a los que pudieron haber sido congregados en Huaca A, lo que implica una lógica ceremonial distinta, quizá derivada de un cambio de las formas ceremoniales o ideológicas sustantivo.

Por último, y para pasar al siguiente apartado, el arte mural desplegado en ambos montículos guarda lógicas distintas. Los ídolos de barro ubicados en la esquina norte de la tercera plataforma están dispuestos de tal forma que cualquier sujeto, sea dentro de una plaza adyacente o fuera de ella, pudo haber observado dichas representaciones artísticas, por lo que se colige que se planificó que el consumo visual de estos rasgos no sea patrimonio de élites determinadas y pequeñas de forma exclusiva. Desconocemos, debido al nivel de preservación de la evidencia, si es que existieron más ídolos en las otras esquinas de la misma u otras plataformas. Esta situación contrasta con el arte mural representado en Huaca $A$, donde los frisos de barro encontrados, en pobres condiciones, se ubicaban en los atrios tanto frontal como trasero, ambos accesos a la cima del montículo. Aunque la altura relativa al suelo natural de la quebrada o a la superficie de la plaza rectangular hundida no es muy pronunciada, estos frisos, de los cuales luego se hablará, posiblemente no pudieron haber sido plenamente apreciados debido a los muros que circundaban al atrio. La visualización de los frisos no era posible si no se accedía a uno de los atrios, los cuales se supone estuvieron restringidos a las élites debido a sus pequeñas dimensiones. Cabe resaltar 
que el atrio suroeste se realizó el hallazgo de una piedra esculpida con dos piedras erguidas, a modo de postes sobre los cuales se asentaría la primera. En esta piedra se representa a un lado la impresión de una mano humana y en el otro, la mayoría de la pieza, el rostro frontal de una serpiente con lengua bífida de la cual emanan dos cuerpos curvilíneos que se entrecruzan hacia atrás (Pozorski, T. y Pozorski, S. 1988: 115-6, fig. 4-5).

\section{DifERENCIAS EN CUANTO}

\section{AL ARTE FIGURATIVO INTRASITIO}

Huaca Moxeke.- Aparte de los ya conocidos y mencionados ídolos de barro (Figs. 3 y 6), Tello registra otros rasgos artísticos relacionados a la arquitectura. Por ejemplo, registra en el vestíbulo un muro de $4.5 \mathrm{~m}$ de alto, donde en la parte superior aparece una hilera de adobes cónicos dirigidos hacia arriba, utilizados en estos casos no de relleno constructivo sino como medio para ganar altura. "Estos adobes estuvieron revestidos con una capa de barro arcilloso sobre la cual presentaban múltiples ornamentaciones en relieve tal como se ven algunas figuras geométricas en cocadas, además en el piso se encuentran restos de alfarería sub-chavín." (Tello 1956: 58. El subrayado es nuestro).

Luego nota que en el muro posterior del vestíbulo hay dos representaciones. "La primera ornamentación consiste en figuras geométricas incisas, rectángulos, rombos, etc., y la segunda en figuras imprecisas en alto relieve." (Tello 1956: 59. El subrayado es nuestro). Los ídolos de Huaca Moxeke fueron muy usados por lo que luego serían sometidos a sucesivos y recurrentes momentos de conservación y refacción. Esto está evidenciado por las sucesivas capas de revestimiento. En sus conclusiones anota lo siguiente:

" $14^{\circ}$ En cuanto a la ornamentación se observa lo siguiente: la superficie exterior del templo estuvo enlucida y cubierta, en parte, por figuras

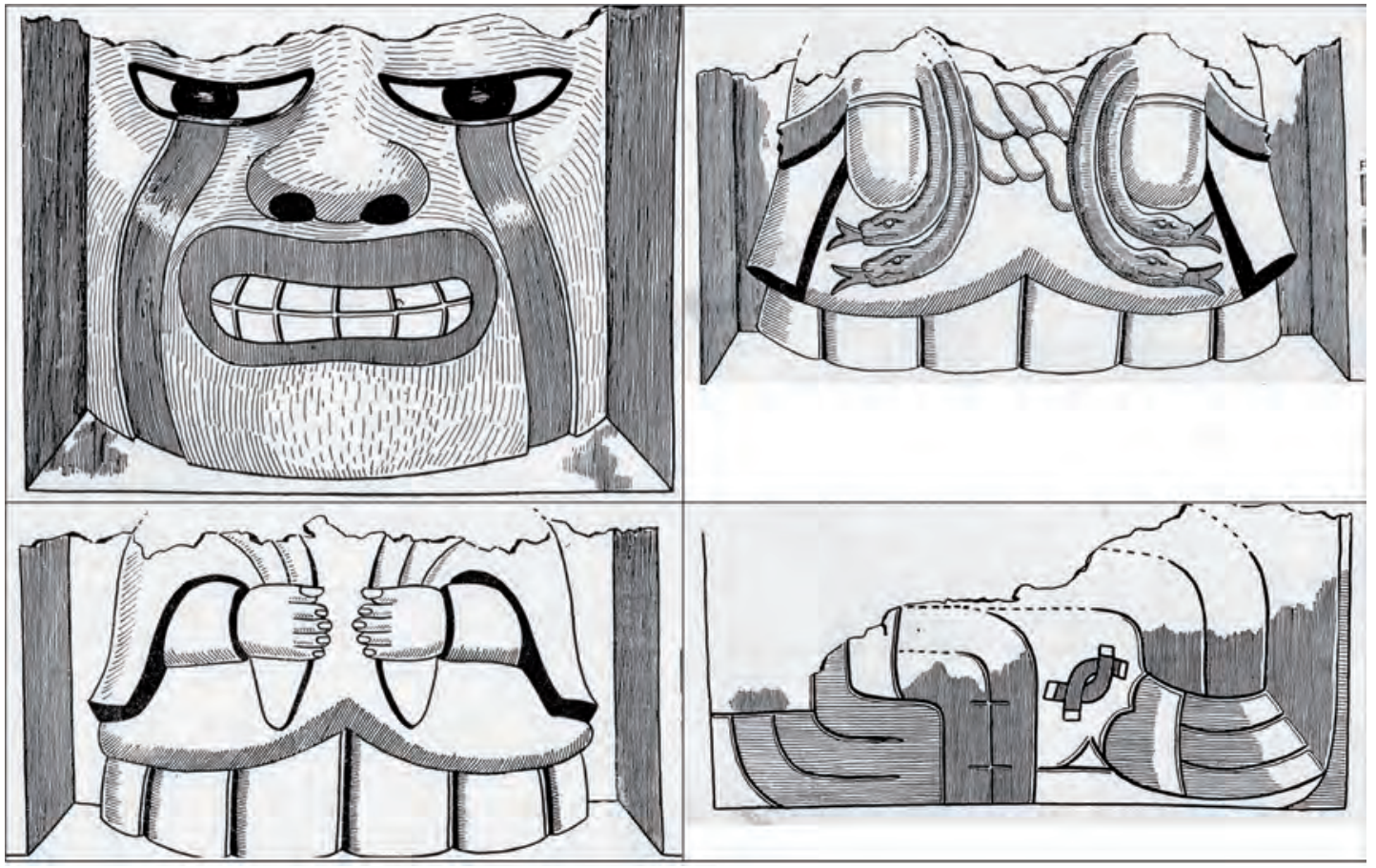

Figura 6: Ídolos de barros provenientes de la esquina curva norte de la tercera plataforma. Tomado de Tello 1956: figs. 38-31. 
en alto y bajo relieves e incisiones y por grandes estatuas hechas con piedra y barro, dentro de nichos enlucidos y pintados. $15^{\circ}$ Las pinturas usadas en la decoración del templo y de las figuras en relieve son tierras colorantes, cuyas tonalidades son blanco, azul, amarillo, negro, rojo, verde y gris." (Tello 1956: 65).

Es una lástima que estas descripciones someras no hayan sido publicadas gráficamente. Sin embargo, para un arte figurativo que supuestamente debiera estar enmarcado dentro de los parámetros del estilo Sechín definido por Bischof, es muy extraña la representación de diseños geométricos, no muy relacionados a lo expresado en los ídolos y diseños inter-cajón de la tercera plataforma.

Huaca A.- Las evidencias de arte figurativo para este montículo y al mismo nivel de evidencia, en tanto soporte dentro de la lógica de muestra sea a públicos pequeños o grandes, son los "felinos" encontrados en 1985. Discrepamos abiertamente con respecto a dicha interpretación. He aquí el relato del hallazgo:

"El área de acceso excavada más elaborada es definitivamente la entrada principal al extremo noreste del montículo. Ascendiendo por la escalinata central hacia la cima del montículo, uno accede al atrio noreste y es inmediatamente confrontado por un enorme muro con frisos adornados por un par de felinos (FIG. 5), uno de los descubrimientos más espectaculares de la temporada de 1985. Cada mitad de esta escultura de barro en bajo relieve bilateralmente simétrica ocupa un espacio de 10 metros del muro en cada lado de la entrada principal al montículo, la cual tiene 2.2 metros de ancho. Una banqueta baja, de $120 \mathrm{~cm}$ de ancho por $25 \mathrm{~cm}$ de alto, resalta a los frisos y puede haber servido como barrera para que los individuos no se acerquen demasiado a las representaciones. Aunque el segmento del muro decorado está solo conservado parcialmente, es claro que el componente principal es un par de figuras completas de felinos de perfil que se miran uno al otro a lo largo de la entrada. La reconstrucción del tamaño y la natura- leza de los felinos están basadas en segmentos conservados de los pies y la cola, así como en comparaciones con otras representaciones de perfiles de felinos las cuales son comunes en la iconografía andina temprana." (Pozorski, S. y Pozorski, T. 1986: 387-8. La traducción es nuestra)

Aparte de estas evidencias presentes en el atrio noreste, se encontraron frisos similares ubicados en su contraparte, el atrio suroeste. Esta evidencia, tal como mencionan los autores, estuvo demasiado deteriorada al momento del hallazgo, aunque por los vestigios puede colegirse que tenía los mismos rasgos que su contraparte antes mencionada. Existe solo una publicación de los Pozorski (Pozorski y Pozorski 1993) donde se relata su hallazgo, de manera somera y poco exhaustiva. Arguyen para este friso suroeste exactamente lo mismo que para su contraparte: la presencia del felino, vinculado al agua y a la irrigación agrícola, y de los diseños geométricos, los cuales simbolizarían la concentración de poder. A continuación presentamos el párrafo exacto donde se describe el hallazgo:

"El friso en el muro trasero del atrio suroeste está pobremente preservado (Fig. 5). Sin embargo, lo suficiente está presente como para indicar que incorporó diseños abstractos algo cuadrangulares los cuales pueden ser las variaciones del símbolo geométrico del "poder", tan prominente en el friso del atrio noreste" (Pozorski y Pozorski 1993: 55).

Henning Bischof afirma que la iconografía más antigua y compleja para el valle de Casma son precisamente estos "felinos", a los cuales describe como "personajes compuestos por especies diferentes, especialmente culebras; ojos excéntricos de fieras con rabillos añadidos en forma de coma; dientes, lenguas o símbolos de "aliento" que indican la presencia de un mascarón simbólico en alguna parte del cuerpo, probablemente en la cintura, y símbolos escalonados." (Bischof 1998:63). En una nota a pie de página hace la siguiente aclaración: "Estas lenguas en la parte central del cuerpo contradicen la reconstrucción como felinos vistos de perfil (Pozorski/Pozorski 1986). Más bien se tratará 

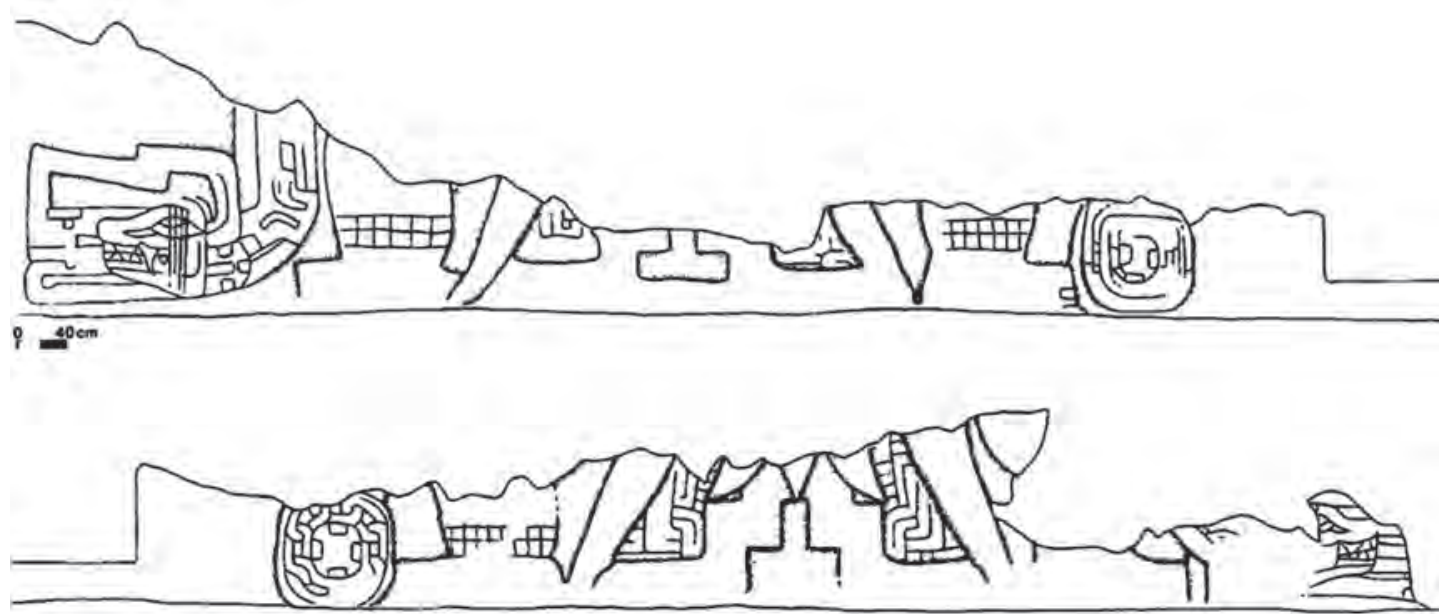

Figura 7: Arte mural de barro hallado en el atrio trasero de Huaca A. Tomado de Pozorski, S. y Pozorski, T. 1986, fig. 5.
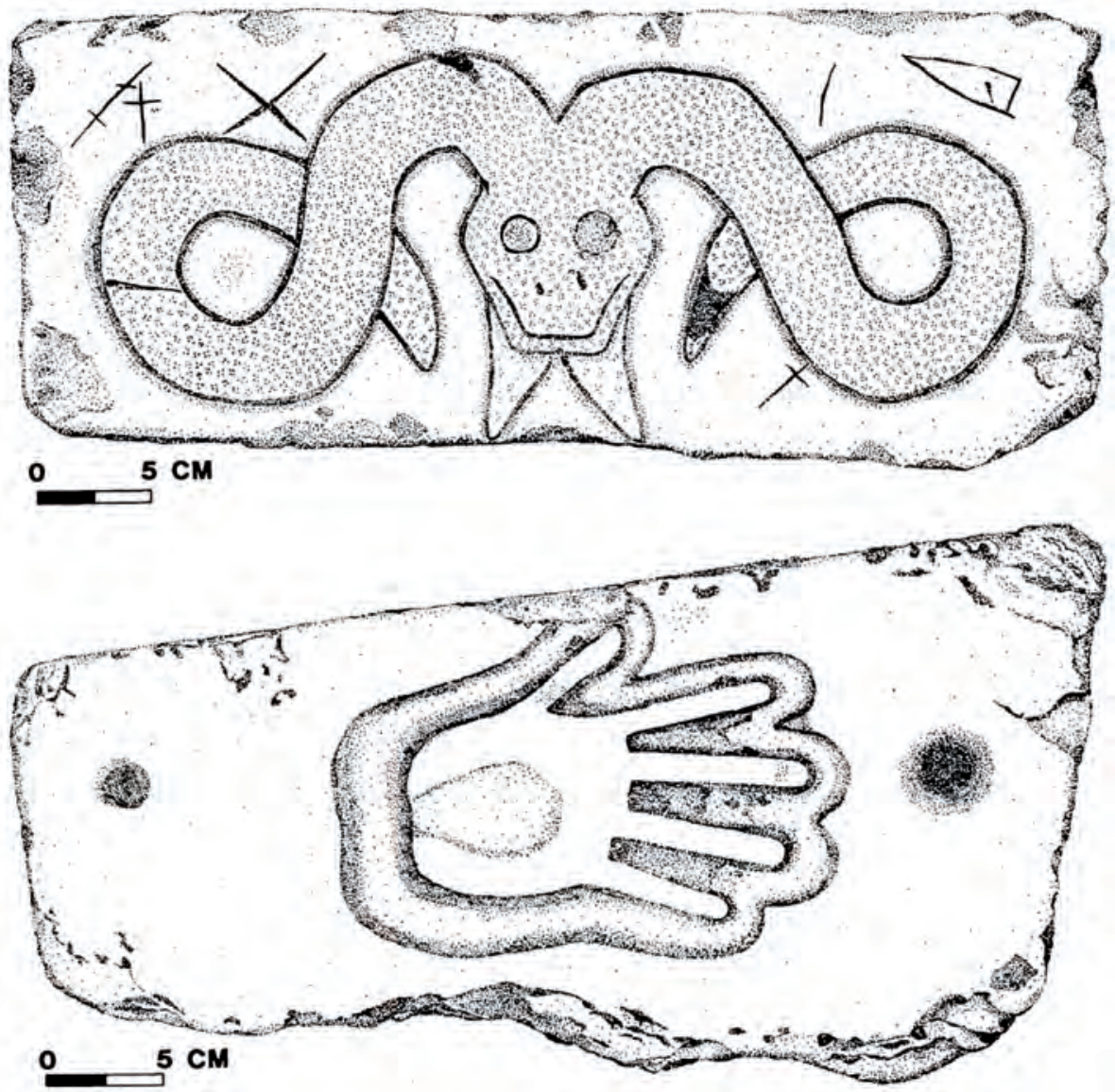

Figura 8: Lápida hallada en esquina curva del atrio frontal de Huaca A. Tomado de Pozorski, T. y Pozorski, S. 1988: 115, figs. 4 y 5. 
[trataría] de representaciones frontales". (Bischof 1998:63, nota 4). Dado que estamos plenamente de acuerdo con lo planteado por Bischof, en la figura 7 se presentan a los murales de barro del atrio suroeste de Huaca A sin la reconstrucción publicada por los Pozorski.

Bischof asocia a estos murales dentro del estilo Chavin A, lo cual deviene en ser precedente directo del estilo Chavín B, representado entre otras obras por el Lanzón, tal como se dijo al inicio. La presencia del mascarón, el personaje al parecer antropormorfo situado en forma frontal y los demás diseños entre zoomorfos y geométricos acusan una estilización de los motivos anteriormente empleados por los estilos Sechín y Punkurí, por lo cual se le podría conferir al montículo y a los motivos una fecha un tanto más tardía que la propuesta. Otra prueba de dicha estilización es la lápida esculpida encontrada en el atrio frontal del edificio, de corte poco realista, siendo el realismo rasgo diagnóstico del estilo Sechín (Fig. 8). Cabe resaltar que esto no es consistente con el planteamiento de Bischof relativo a que la Huaca Moxeke y sus ídolos de barro pertenecen al estilo Chavín B. Pensamos que estos últimos pertenecen a un estilo y tiempo previo al propuesto por el autor antes mencionado, por las semejanzas entre estos íconos con los personajes principales del sitio de Cerro Sechín, los cuales muestran extremas similitudes en cuanto a la forma de los ojos, la nariz y la boca (Fig. 9).

A nuestro parecer, existen muy pocos rasgos que puedan vincular sincrónicamente al arte desarrollado en Huaca Moxeke y en Huaca A. Esto contrastado con otras líneas de evidencia parece sugerir un cambio tangencial en la historia del asentamiento de Pampa de Llamas-Moxeke y de la sociedad que a ella se circunscribió. Probablemente la migración de ideas, más que la complejización de las mismas, haya sido el factor decisivo en toda esta gama de cambios atestiguados. Dicha migración, pensamos, probablemente haya implicado también movimiento de poblaciones. No estamos seguros si el arte desarrollado en Hua- ca A es foráneo o no, simplemente notamos que la diferencia es substancial, lo cual podría llevar a sospechar lo anteriormente señalado. Este cambio bien puede estar relacionado a lo que posteriormente sería el fenómeno Chavín, dado que los diseños que aparecen en Huaca Moxeke, así como en otros asentamientos de la costa peruana, pasarían a barroquizarse aun más en el estilo Chavín B.

\section{CONCLUSIONES E IMPLICANCIAS DE LA HIPÓTESIS PLANTEADA}

En resumidas cuentas, después de toda la argumentación, planteamos que Huaca A y Huaca Moxeke no funcionaron al unísono. El emplazamiento elevado de Huaca A pareciera simbolizar una imposición de culto, tal como el atestiguado en Pachacamac para con el templo del Sol (Fig. 10). La diferencia en la lógica de ganar prestigio simbolizado en altura puede responder a formas de pensar distintas, quizá no precisamente generacionales. Una vez propuesta la misma funcionalidad para ambos montículos, la diferencia en cuanto a las formas de actividad ceremonial entre ambos monumentos, uno más restringido que el otro, hace sostener mejor la idea de la imposición. La diferencia en la utilización de materiales constructivos es consistente con la dimensión arquitectónica de esta propuesta. Los fechados radiocarbónicos no bien logrados dejan entrever la fecha asignada a Huaca A, así como a todo el complejo, más aun a Huaca Moxeke, la cual nunca ha sido fechada radiocarbónicamente. La poca o nula vinculación entre los discursos iconográficos expresados en ambos monumentos aboga, sumado a lo anteriormente citado, a un cambio de las formas ceremoniales o ideológicas tangencial una vez derrotado el culto expresado en Huaca Moxeke, el cual pensamos podría estar relacionado al arte desarrollado en Cerro Sechín. Al parecer en Huaca Moxeke se rendía culto a seres representados en imágenes de rostros ligeramente expresivos, mientras que el despliegue agresivo de diseños en Huaca A hace sugerir la presencia de personajes monstruosos en conjunción con animales. El culto dirigido en Huaca A parece ser más 


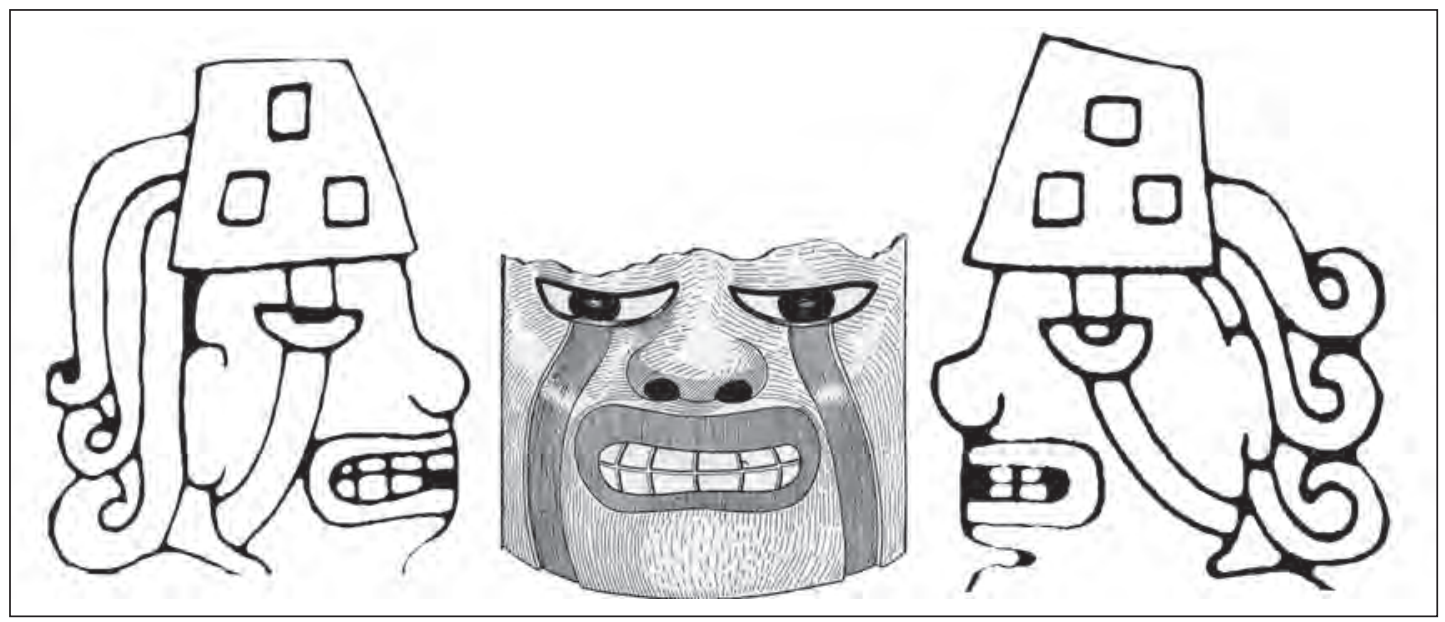

Figura 9: Semejanzas entre rostros de personajes principales del sitio de Cerro Sechín con rostro de ídolo conservado en Huaca Moxeke. Nótese las grandes semejanzas en cuando a forma de ojos, boca y nariz. Redibujado a partir de Tello 1956.

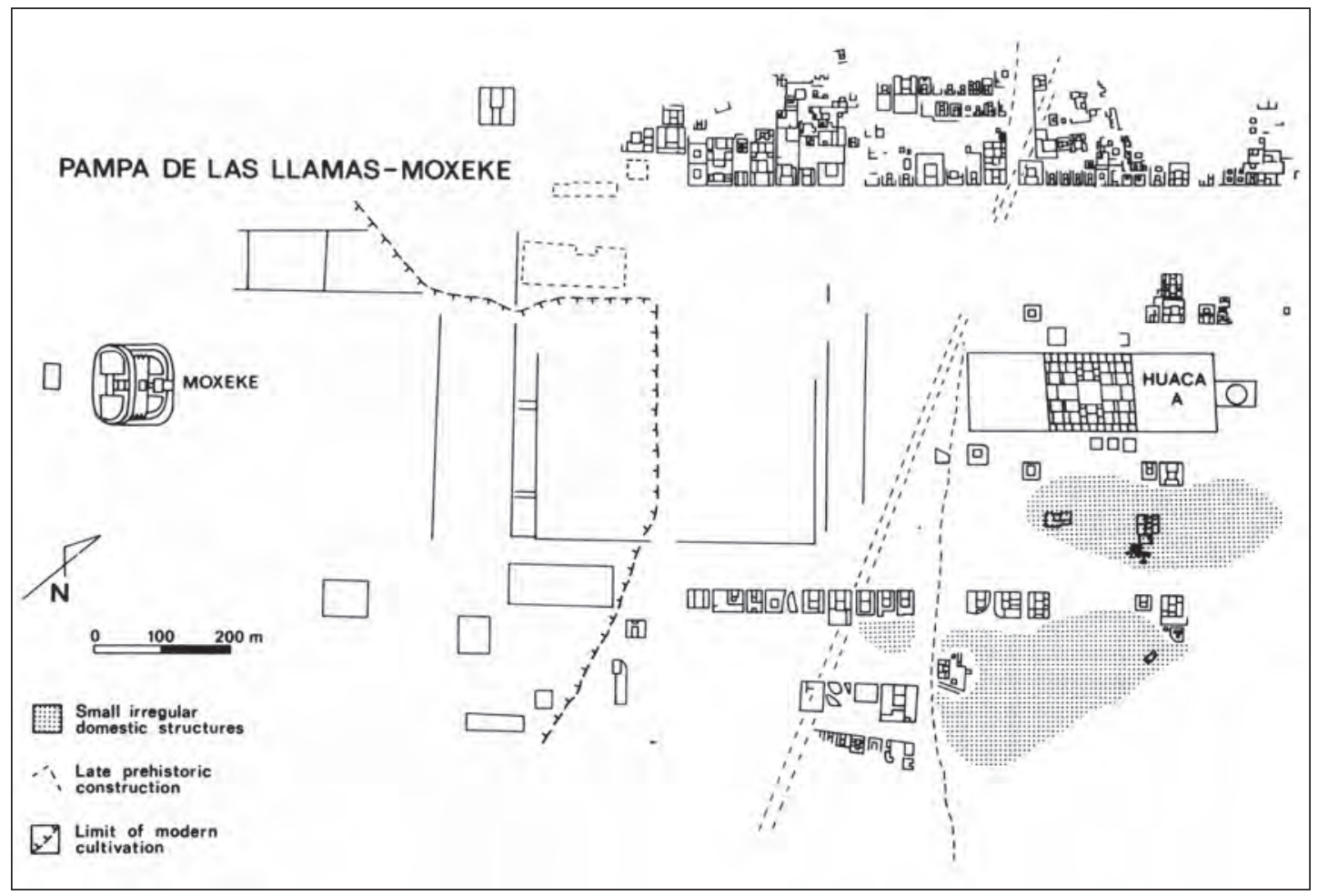

Figura 10: Plano de Pampa de Llamas-Moxeke según Pozorski, S. y Pozorski, T. 1989: 21, fig. 1. 
agresivo, intimidante y restringido, quizá más relacionado con el posterior culto Chavín. Me atrevería a decir que también es probable que Huaca Moxeke pueda incluso proceder del Arcaico Tardío dadas las posibles reminiscencias de arte tipo Punkurí, habida cuenta los motivos geométricos descritos por Tello y los fechados precerámicos que se le asignan a Cerro Sechín (Bischof 1998, Fuchs 1997); probablemente, tal como Cerro Sechín, el funcionamiento de este edificio abarque un lapso de tiempo comprendido entre los últimos siglos del Arcaico Tardío y los primeros del Formativo Temprano.

Si acordamos que la religión en el periodo Formativo fue "el" agente de cambios trascendentales, y que la condición de centro ceremonial implica la reproducción de atmósferas de producción inmaterial (léase rituales), lo que hace que el crecimiento vertical de estructuras pueda garantizar la distinción marcada de espacios y el uso de estos en interacción con la experiencia humana, sea individual o grupal (Rick 2008, Vega-Centeno 2006, Moore 1996), es coherente pensar que una imposición de culto sería una estrategia eficaz para lograr una garantía de toma de poder y decisión en la vida sociopolítica del valle de Casma.

Desde luego esta hipótesis tiene limitaciones debido a la poca representatividad de la muestra. Es posible que el estado de conservación de los frisos de Huaca A no sean suficientes como para confirmar esta hipótesis, sin embargo, al igual que lo propuesto para con los fechados radio-carbónicos, considero que es más que suficiente a nivel de indicio como para formular lo aquí planteado. Los datos presentados son preventivos y responden también al hecho de que muy poco de lo excavado en el complejo ha sido publicado. Se hace necesario que se publique más acerca de las temporadas de excavación, del análisis de los datos; compendiarlos sería una excelente iniciativa debido a que para el complejo hay mucha información pero publicada de forma dispersa y no ordenada. De todas las campañas de excavación solo se ha publicado un artículo exclusivo, los demás datos aparecen salpicados en sendas publicaciones.
Desde luego la propuesta aquí planteada tiene implicancias, pero el responderlas sería caer en discusiones poco productivas en tanto no tengamos más datos empíricos para poder sostenerlas. Sin embargo planteamos algunas. ¿Cómo cambia el panorama si es que se logra probar la no contemporaneidad de ambos montículos, Huaca A y Moxeke, en base a la propuesta de Pozorski y Pozorski 1986, 1987, relativa a un estado que domina la escena política en la parte media del valle de Casma? ¿Qué implicancias puede traer en el valle la introducción de un sitio de filiación externa dentro de un panorama social netamente endémico o local vinculado al estilo Sechín? ¿Cómo queda ubicado el rol de la arquitectura intermedia del complejo de Pampa de Llamas-Moxeke? Respecto a lo último bien se podría tener una imagen sesgada debido al hecho de que muchas estructuras de tamaño pequeño o intermedio ligadas a Huaca Moxeke han desaparecido por haber estado en la parte arable actual del valle, de modo que la muestra de arquitectura intermedia parece corresponder exclusivamente a la Huaca A, la correspondiente a Huaca Moxeke se habría perdido para siempre, excepto por algunos fragmentos de estructuras, muy pequeños, destruidos y saqueados.

Para culminar, deseamos mencionar que no compartimos el pesimismo expresado por Shelia y Thomas Pozorski en la publicación de 1986 (p. 384). Creemos, en base a continuas y muy recurrentes visitas al montículo, que Huaca Moxeke tiene aún un potencial muy grande por ser explotado, y que gran parte de las ideas vertidas en este trabajo podrían ser resueltas si es que excavamos en dicho monumento. Si bien es cierto que la arquitectura contigua a este monumento, así como las primeras plazas cuadrangulares, por estar en la parte arable del asentamiento se han perdido o corren peligro inminente de perderse, el montículo está ahí, los pozos de huaqueo no son profundos y su carácter masivo hace que lo más seguro sea que sus etapas constructivas previas a la identificada por Tello en los años 30's aún puedan reconocerse, así como los materiales y áreas de actividad diferenciadas diacrónicamente, lo cual nos permita tener una mejor representación de su rol dentro del periodo Formativo en el valle de Casma y en general en los Andes Centrales. 


\section{Agradecimientos}

Quiero agradecer ante todo a Rafael Vega-Centeno, porque un buen día asistí a una clase que no me correspondía y de buena gana soltó la propuesta ritual para Huaca A, dato al cual rastreé hasta que mis indagaciones llegaron a tomar la forma ahora expuesta; luego de ello durante una grata conversación/almuerzo me brindó muy buenos consejos que ayudaron a mejorar el texto. Agradezco a Henry Tantalean por las sugerencias brindadas, las cuales por su pertinencia seguí al pie de la letra. Agradezco también a Elizabeth Cruzado a quien un buen día, frio y lluvioso en Chavín, pedí revisar una temprana propuesta relativa a este tema. Aunque los arreglos hechos en las imágenes aquí presentadas no sean tan bien logrados, quiero agradecer a mi hermano Emmanuel por enseñarme las pautas básicas del programa CorelDRAW X4. Por último, pero para nada menos importante, agradezco a mis padres, Rebeca y Augusto, quienes me han permitido estudiar y producir en esto que hago: Arqueología. Está demás decirlo, que la responsabilidad de cualquier aseveración, error o falencia es enteramente mía.

\section{REFERENCIAS BIBLIOGRÁFICAS}

Álvarez, Alcides; Espinoza, Juan E.

1997 "Mandinga: Un asentamiento tipo Aldas en el valle de Huarmey". Manq 'a Llaqta 1:27-49.

Bazán, Augusto

2008a "Relación comunidad - patrimonio arqueológico en el sector Moxeke, valle de Casma, Perú. Aproximación al entendimiento entre arqueólogos y poblaciones". IberoamericaGlobal 1 (4), pp. 165 186. <http://iberoamericaglobal.huji. ac.il/Num4pdf/Art_Bazan_4.pdf $>$.

2008b "Definiendo la frontera sur del patrón Casmeño. Estudio del sitio de Huaricanga, Valle de Fortaleza”. Informe final para el curso de Prácticas Pre Profesionales III, dirigido por el Dr. Idilio Santilla. Universidad Nacional Mayor de San Marcos. $<$ http://www.scribd.com/doc/11656183/
Frontera-Sur-Del-Patron-Casma-Augusto-Bazan-2008>.

2010 "El Castillo de Huaricanga, un Sitio Formativo en el valle de Fortaleza". Revista de Investigaciones del CEAR 7, pp. 15-52.

Bird, Junius

1948 "Preceramic culture in Chicama and Virú". American Antiquity 12(4): 21-28.

Bird, Junius; Hyslop, John; Skinner, Milica

1985 "The Preceramic Excavations at the Huaca Prieta Chicama Valley, Peru". Anthropological papers of the American Museum of Natural History, vol. 62, pt.1. New York: American Museum of Natural History.

Bischof, Henning

1994 "Toward the definition of pre- and early Chavin art styles in Peru". Andean Past 4, pp. 169-228.

1995 "Cerro Sechín y el arte temprano centro-andino". Arqueología de Cerro Sechín. T. II, Escultura. Lerner, S., Cárdenas, M. y Kaulicke, P. eds., pp. 157-184. Lima: Pontificia Universidad Católica del Perú.

1997 "Cerro Blanco, valle de Nepeña-Perú - Un sitio del Horizonte Temprano en emergencia”. Archaeologica Peruana 2. Arquitectura y Civilización en los Andes Prehispánicos. Elisabeth Bonnier y Henning Bischof Eds., pp. 203-234. Mannheim: Sociedad arqueológica peruanoalemana - Reiss-Museum.

1998 "El Periodo Inicial, el Horizonte Temprano, el estilo Chavín y la realidad del proceso formativo en los Andes centrales". Encuentro Internacional de Peruanistas Tomo I. Estado de los Estudios HistóricoSociales sobre el Perú a fines del Siglo XX, pp. 57-85. Lima: Universidad de LimaUnesco-Fondo de Cultura Económica.

Burger, Richard

1986 "The prehistoric occupation of Chavin de Huantar, Peru". University of California publications in anthropology 14. Berkeley: University of California Press.

1989 "The pre Chavin stone sculpture of Casma and Pacopampa". Journal of Field Archaoelogy 16(4), pp. 478-485. 
1992 Chavin and the Origins of Andean Civilization. London: Thames and Hudson.

1993 Emergencia de la Civilización en los Andes: Ensayos de Interpretación. Lima: Universidad Nacional Mayor de San Marcos.

1996 "Chavín". Andean Art at Dumbarton Oaks. Hill Boone, E. Ed. pp. 45-86. Washington, D.C.: Dumbarton Oaks Research Library and Collection.

Cárdenas, Mercedes

1999 "Material diagnóstico del periodo Formativo en los Valles de Chao y Santa, Costa Norte del Perú". Boletín de Arqueología PUCP 2. Perspectivas Regionales del Período Formativo en el Perú. Peter Kaulicke Ed., pp. 61-82. Lima: Fondo Editorial de la PUCP.

Castro, Pedro; Chapman, Robert; Gili, Sylvia; Lull, Vicente; Micó, Rafael; Rihuete, Cristina; Risch, Roberto; Sanahuja, María Encarna

1996 "Teoría de las prácticas sociales". Complutum Extra 6(11), pp. 35- 48.

Collier, Donald

1962 "Archaeological Investigations in the Casma Valley, Peru". Akten des 34. Internationalen Amerikanistenkongress, pp. 411-417. Viena: Congreso Internacional de Americanistas.

Daggett, Richard

1984 The Early Horizon Occupation of the Nepeña Valley, North Central Coast of Peru. Tesis Doctoral. Universidad de Massachusetts.

Fuchs, Peter

1997 "Nuevos datos arqueométricos para la historia de ocupación de Cerro SechínPeriodo Lítico al Formativo". Archaeologica Peruana 2. Arquitectura y Civilización en los Andes Prehispánicos. Elisabeth Bonnier y Henning Bischof Eds., pp. 145161. Mannheim: Sociedad arqueológica peruano- alemana - Reiss-Museum.

Fuchs, Peter; Patzschke, Renate; Schmitz, Claudia; Yenque, Germán; Briceño, Jesús

2008 "Investigaciones arqueológicas en el sitio de Sechín Bajo, Casma”. Boletín de Arqueología PUCP 10. Procesos y expresiones de poder, identidad y orden tempranos en Sudamérica. Primera parte, pp.
111-136. Peter Kaulicke y Tom Dillehay Eds. Lima: Fondo Editorial de la PUCP.

Fung, Rosa

1969 "Las Aldas: su ubicación dentro del proceso histórico del Perú antiguo". Dédalo: revista de arte e arqueología 9-10. Sao Paulo.

1972 "Nuevos datos para el período de cerámica inicial en el valle de Casma". Arqueología y sociedad 7-8, pp. 1-12.

2004 Quehaceres de la arqueología peruana: compilación de escritos. Lima: Museo de arqueología y antropología, Centro cultural de San Marcos. Universidad Nacional Mayor de San Marcos

Fung, Rosa; Williams, Carlos

1977 "Exploraciones y excavaciones en el valle de Sechín, Casma". Revista del Museo Nacional, Tomo XLIII, pp. 111-155. Lima: Museo Nacional de la Cultura Peruana.

Grieder, Terence

1976 "A dated sequence of building and pottery at Las Haldas". Nawpa Pacha 13, pp. 99-120.

Kaulicke, Peter

1994 Los Orígenes de la Civilización Andina. Arqueología del Perú. Tomo I de Historia General del Perú. José Antonio del Busto (Editor General). Lima: Editorial Brasa.

1995 “Arte y Religión en Cerro Sechín”. Arqueología de Cerro Sechín. T. II, Escultura. Lerner, S., Cárdenas, M. y Kaulicke, P. eds. pp. 185-222. Lima: Pontificia Universidad Católica del Perú.

2008 "La economía en el Periodo Formativo". Economía Prehispánica. Carlos Contreras Ed., pp. 137-230. Lima: Instituto de Estudios Peruanos - Banco Central de Reserva del Perú.

Lanning, Edward P.

1967 Peru before the Incas. New Jersey: Prentice-Hall.

Larco, Rafael

1938 Los Mochicas, Vol. I. Lima: Casa Editora "La Crónica y Variedades".

Lumbreras, Luis Guillermo

1971 "Towards a re-evaluation of Chavín". Dumbarton Oaks Conference on Chavin. 
Elizabeth Benson Ed., pp. 1-28. Washington: Dumbarton Oaks Research Library and Collection.

1988 "Childe y la tesis de la revolución urbana: la experiencia central andina". Estudios sobre las revoluciones neolítica y urbana. Linda Manzanilla ed., pp. 349-366.

2004 "Un Formativo sin cerámica y cerámica pre formativa”. Estudios Atacameños. Arqueología y Antropología Surandinas 32, pp. 11-34.

Moore, Jerry D.

1996 Architecture and Power in the Ancient Andes. The Archaeology of Public Buildings. Cambridge: Cambridge University Press.

Pozorski, Shelia; Pozorski, Thomas

1986 "Recent Excavations at Pampa de las Llamas-Moxeke, a Complex Initial Period Site in Peru". Journal of Field Archaeology 13(4), pp. 381-401. Boston: The association for Field Archaeology, Boston University.

1987 Early Settlement and Subsistence in the Casma Valley, Peru. Iowa City: Iowa Press.

1989 "Planificación Urbana Prehistórica en Pampa de las Llamas-Moxeke, Valle de Casma”. Boletín de Lima 65, pp. 19-30.

1990 "Reexaminig the Critical Preceramic/ Ceramic Period Transition: New Data from Coastal Peru". American Anthropologist. 92(2), pp. 481-491.

1992 "Early civilization in the Casrna Valley, Peru". Antiquity 66, pp. 845-870.

2002 "The Sechín Alto complex and its place within Casma Valley Initial Period development". Andean Archaeology I: variations in socio-political organization, pp. 21-51. New York: Kluwer Academic/ Plenum.

2006 "Las Haldas: An expanding Initial Period Polity of Coastal Peru". Journal of Anthropological Research 62, pp. 27-52.

Pozorski, Thomas

1975 "El Complejo de Caballo Muerto: Los Frisos de barro de la Huaca de los Reyes". Revista del Museo Nacional XLI, pp. 211-251.
Pozorski, Thomas; Pozorski, Shelia

1987 "Chavin, the Early Horizon and the Initial Period". The Origins and Development of the Andean State. Haas, J., Pozorski, S., Pozorski, T. Eds. Pp. 36-46. Cambridge: Cambridge University Press.

1988 "An early stone carving from Pampa de las Llamas-Moxeke, Casma Valley, Peru". Journal of Field Archaeology 15(1), pp. 114-119.

1990 "Reply to The Pre Chavin Stone Sculpture of Casma and Pacopampa". Journal of Field Archaeology 17(1), pp. 110-111.

1992 "Early stone bowls and mortars from northern Peru". Andean Past 3, pp. 165186.

1993 "Early Complex Society and Ceremonialism on the Peruvian North Coast". El Mundo Ceremonial Andino. Senri Ethnological Studies 37. Millones, L.; Onuki, Y. Eds., pp. 45-68. Tokio: National Museum of Ethnology.

2005 "Architecture and Chronology at the Site of Sechín Alto, Casma Valley, Peru". Journal of Field Archaeology 30 (2), pp. 143-161.

Proulx, Donald

1985 "An analysis of the early cultural sequence of the Nepeña Valley, Peru". Research Report, 25, Department of Anthropology, University of Massachusetts.

Rick, John

2008 "Un análisis de los centros ceremoniales del Periodo Formativo a partir de los estudios en Chavín de Huántar”. Boletín de Arqueología PUCP 10. Procesos y expresiones de poder, identidad y orden tempranos en Sudamérica. Primera parte, pp. 201-214. Peter Kaulicke y Tom Dillehay Eds. Lima: Fondo Editorial de la PUCP.

Rick, John; Rodríguez Kembel, Silvia

2004 "Building authority at Chavín de Huántar: Models of social organization and development in the Initial Period and Early Horizon". Andean Archaeology. Helaine Silverman Ed., pp. 51-76. Malden, MA: Blackwell Publishers. 
Rick, John; Rodríguez Kembel, Silvia; Mendoza Rick, Rosa; Kembel, John

1999 "La arquitectura del complejo ceremonial de Chavín de Huántar: documentación tridimensional y sus implicancias". Boletín de Arqueología PUCP 2. Perspectivas Regionales del Período Formativo en el Perú. Peter Kaulicke Ed., pp. 181 . 214. Lima: Fondo Editorial de la PUCP.

Rodriguez-Kembel, Silvia

2001 Architectural Sequence and Chronology at Chavin de Huantar, Peru. Tesis Doctoral. Universidad de Stanford.

Rowe, John

1967 "Form and meaning in Chavin art". Peruvian Archaeology. Selected Readings. Rowe, J., Menzel, D. Eds. Pp. 72-103. Palo Alto: Peek Publications.

1971 "The influence of Chavin Art on later styles". Dumbarton Oaks Conference on Chavin. Benson, E. Ed. Pp. 101-124. Washington D.C.: Dumbarton Oaks.

Ramón, Gabriel

2005 "Periodificación en arqueología peruana: genealogía y aporía". Bulletin de L'Institut Français d'Etudes Andines 34(1), pp. 5-33.

Tello, Julio Cesar

1943 "Discovery of the Chavín culture in Peru". American Antiquity 9(1): 135160.

1956 Arqueología del valle de Casma. Culturas: Chavin, Santa. Huaylas Yunga y sub-Chimú. Informe de los trabajos de la expedición arqueológica al Marañón de 1937. Publicación antropológica del archivo Julio C. Tello, Vol. 1. Lima: Universidad Nacional Mayor de San Marcos.

1960 Chavin: Cultura matriz de la civilización andina. Primera parte. Revisada por Toribio Mejía Xespe. Publicación antropológica del Archivo "Julio C. Tello" n 2. Lima: Universidad Nacional Mayor de San Marcos

Thompson, Donald

1962 "Additional Stone Carving from the North Highlands of Peru". American Antiquity 28 (2), pp. 245-246.
1964 "Formative Period Architecture in the Casma Valley, Peru". Actas y memorias del XXXV Congreso Internacional de Americanistas, pp. 205-212. México D.F: Congreso Internacional de Americanistas.

1974 "Arquitectura y patrones de establecimiento en el valle de Casma". Revista del Museo Nacional, Tomo XL, pp. 1-26. Lima: Museo Nacional de la Cultura Peruana.

Vega-Centeno, Rafael

1998 "Patrones y convenciones en el arte figurativo del Formativo Temprano en la Costa Norte de los Andes Centrales". Bulletin de L'Institut Français d'Etudes Andines 27(2), pp. 183-211.

1995 Arquitectura monumental y arte figurativo del formativo temprano en la costa nor-central del Perú. Tesis de Licenciatura. Pontificia Universidad Católica del Perú.

2006 "El estudio arqueológico del ritual". Investigaciones Sociales 16, pp. 171-192.

Willey, Gordon

1970 "El problema de Chavín: revisión y crítica". 100 años de arqueología en el Perú. Roger Ravines Ed., pp.161-211. Lima: IEP - Petroperú.

Williams, Carlos

1978-80 "Complejos de Pirámides con Planta en U. Patrón arquitectónico de la Costa Central". Revista del Museo Nacional, Tomo XLIV, pp. 95-110. Lima: Museo Nacional de la Cultura Peruana.

1980 "Arquitectura y Urbanismo en el Antiguo Perú". Historia del Perú, Tomo 8, pp. 369-585. Barcelona: Editorial Juan Mejía Baca.

1985 "A scheme for the early monumental architecture of the central coast of Peru". Early ceremonial architecture in the Andes, pp. 227-240. Christopher Donnan Ed.. Washington, D.C: Dumbarton Oaks research library and collection.

Ziólkowski, Mariusz; Pazdur, Mieczyslaw; Krzanowski, Andrzeg; Michczynski, Adam

1994 Andes: radiocarbon database for Bolivia, Ecuador and Peru. Varsovia: Warsaw University Institute of archaeology Gliwice Radiocarbon Laboratory of the Institute of Physics. 